\title{
Effects of Pilot Hole Diameter and Depth on Screw Driving Torques in Plywood
}

\author{
Onder Tor, ${ }^{\mathrm{a}}$ Emre Birinci, ${ }^{\mathrm{b}}$ Lingling $\mathrm{Hu},{ }^{\mathrm{c}, *}$ and Chen Chen ${ }^{\mathrm{d}}$ \\ Factors affecting screw driving torques in plywood were investigated in \\ this work. The factors were number of layers (7 and 9), pilot hole diameter \\ (3.0 and $3.5 \mathrm{~mm}$ ), pilot hole depth $(60$ and $80 \%$ of the thickness of \\ specimen), and thickness of the metal plate $(7.5$ and $10 \mathrm{~mm})$. Screw \\ driving torques were studied in oriented strandboard, medium-density \\ fiberboard, particleboard, and some wood-plastic composites. There is no \\ such information about screw driving torques in plywood (PW). Therefore, \\ this study focused on the plywood made of aspen (Populus tremula L.). \\ The mean seating torque (SET) values ranged from 0.31 to $0.69 \mathrm{~N} \cdot \mathrm{m}$, \\ whereas mean stripping torque (STT) values ranged from 0.50 to $4.7 \mathrm{~N} \cdot \mathrm{m}$. \\ The ratios of STT/SET were between 2 and 5 in PW with seven layers, \\ whereas the ratios were between 4 and 7 in PW with nine layers. The \\ results indicated that the four main effects of SET and STT were \\ statistically significant with $p$-values of $<0.0001$.
}

Keywords: Screw; Face orientation; Seating torque; Stripping torque

Contact information: a: Department of Forest Industry Engineering, Faculty of Forestry, Kastamonu University, Kastamonu, Turkey, 37200; b: Kastamonu University, Arac Rafet Vergili Vocational School and Higher Education, Forestry and Forest Products Program, Kastamonu, Turkey, 37800; c: Department of Industrial Design, Zhejiang A\&F University, Hangzhou, China; d: College of Furnishings and Industry Design, Nanjing Forestry University, Nanjing, Jiangsu, China, 210000;

*Corresponding author: radiant00@63.com

\section{INTRODUCTION}

One of the most important mechanical properties of wood-based materials is their screw-driving performance in terms of screw-driving torques. Screws that are insufficiently tightened to their materials with low driving torque might cause screw seating problems. Conversely, applying excessive driving torque on the screw can cause screw stripping problems for the materials. Additionally, over-torque can damage the materials on account of the failure of a fastener from overstressing the screw and secured areas in the materials. Carroll (1970) measured the flush and maximum screw-driving torques in PB (particleboard) using a dial-type manual torque wrench at a loading rate of approximately $8 \mathrm{~s}$ per revolution. The flush condition was defined as that in which the screw head was fully touching the surface of the material. Carroll (1970) also reported that stripping of wood screws occurred after one full turn of the wrench beyond the point where the lag screw was in full contact with the side member.

Limited research has been conducted on the factors on screw-driving torques in wood-based materials. Recent studies (Robert 2010; Tor et al. 2015; Yu et al. 2015) defined critical screw-driving torques based on the torque-time curves of screws in oriented strand-board (OSB), PB, and plastics. The torque value at the turning point where the screw seated, i.e., the screw head fully touched the surface of the material, was termed as "seating 
torque" (SET). Turning the screw beyond the SET point began the process of tightening the tested material. The torque dropped when the turning torque passed its maximum value, which was the second peak, termed as "stripping torque" (STT). The sharp drop in the screw-driving torque beyond the second peak was because of the formed threads being stripped by the screws. Tor et al. $(2015,2016)$ evaluated the effects wood-based composite type, embedded screw orientation, and pilot hole diameters on critical torques through driving screws into 18.26-mm-thick OSB and PB materials. Yu et al. (2015) investigated the effects of pilot hole diameter, embedded screw orientation, and PB type (19 mm thick) on critical torques through driving screws into 19-mm-thick PB materials. The National Particleboard Association (1968) reported that the maximum torque required to set a No. 8 wood, or self-tapping screw, in PB materials ranged from 2.26 to $5.65 \mathrm{~N} \cdot \mathrm{m}$. The combinations with ratios greater than three are suitable for using power tools, but for those combinations with ratios less than three, more skills are required from the operators (Robert 2010).

Studies have shown that driving screws into any kind of materials by manual, pistol-grip powered, or battery-powered screwdrivers may cause health problems, such as cumulative injuries, which occur in connective soft tissues, especially to tendons and their sheaths (Kroemer 1989). These kinds of injuries are called Cumulative Trauma Disorders (CTD), and they are caused or aggravated by repetitive motions, including forceful movements, sustained or constrained postures, and vibrations. They are common in the hand-wrist-forearm area and in the shoulders and neck. This disorder is additionally called rheumatic disease, cervicobrachial disorder, over-use injury, cumulative trauma injury, repetitive motion injury, repetition strain injury, and osteoarthritis (Chatterjee 1987; Corlett 1988; Armstrong et al. 1999). Carpal tunnel syndrome is one of the most common problems that increase pressure on the nerves, muscles, and tendons in the hand and wrist area due to highly repetitive manual tasks using a screwdriver (Herbert et al. 2000). Another study reported that tool weight was not a significant factor related to effort and stress when using a screwdriver in a vertical position with a properly adjusted tool balancer (Johnson and Childress 1988). However, the tool weight together with elevated arm lengths was always a significant factor in terms of affecting the shoulder muscles (Ortengren et al. 1991; Cederqvist and Lindberg 1993).

A typical torque-time curve is shown in Fig. 1 and recorded during the complete course of driving screws into faces of tested PB materials. This process can be divided into the three phases of thread forming and screw seating (phase I), clamping (phase II), and screw stripping (phase III) (Robert 2010; Tor et al. 2015; Yu et al. 2015; Kuang et al. 2017). In phase I, the screw-driving torque gradually increased as the screw was cutting PB materials to form threads, and meanwhile overcoming friction force between the contacting surface of the screw and PB materials, and then the screw became seated once the torque reached its SET value. In phase II, right after reaching its SET value, the screw started its tightening process with sharply increasing torque to its STT value. In phase III, the torque value dropped dramatically once the torque passed its STT point.

The purpose of this study was to obtain practical information about SET and STT into the face of PW material, which has important criteria in the case of clamping pieces by a screw. The objectives were: 1) to obtain mean SET and STT values of a screw driven into the face of PW material; 2) investigate the effects of number of PW layers, pilot hole diameter, pilot hole depth, and thickness of metal plate on SET and STT of screw; and 3) 
estimate the mean SET and STT values of a screw driven into the face of PW material evaluated in this study with a developed estimation equation.

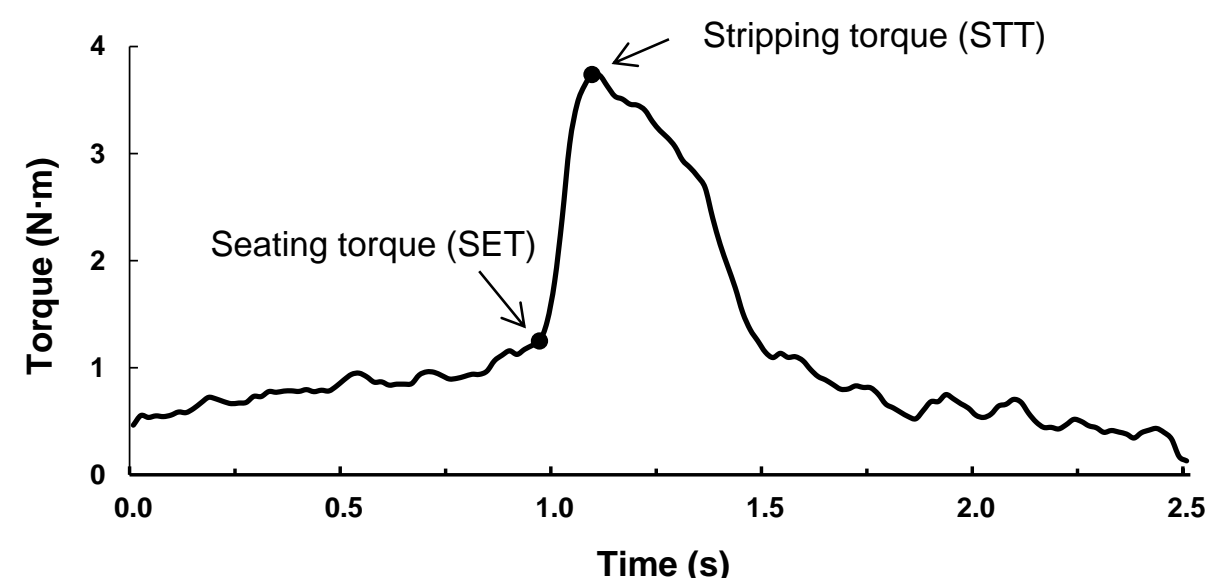

Fig. 1. A typical torque-time curve of driving screws into faces of tested particleboard materials (Tor et al. 2019)

\section{EXPERIMENTAL}

\section{Materials}

Half-sized aspen (Populus tremula L.) PW panels were provided and measured $1250 \mathrm{~mm}$ long $\times 1250 \mathrm{~mm}$ wide from Karabük, Turkey. Two different thicknesses of plywood panels were selected, $11 \mathrm{~mm}$ with seven veneer layers and $14 \mathrm{~mm}$ with nine veneer layers (Fig. 2).

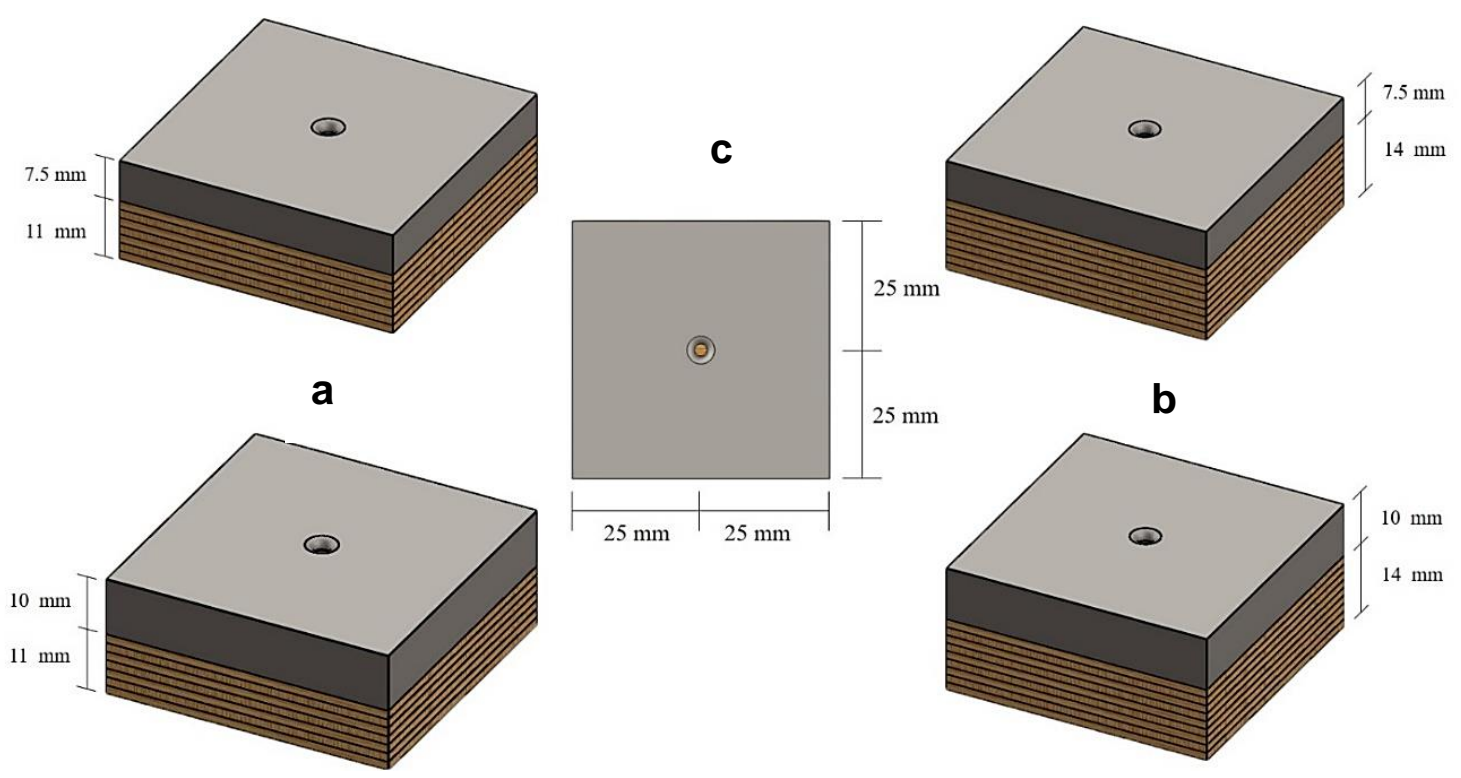

Fig. 2. Dimensions of the PW face specimen: a) test specimen with 7 layers and 7.5- and 10-mmthick metal plate on it; b) test specimen with 7 layers and 7.5- and 10-mm-thick metal plate on it; c) the view from the top of the PW specimen 
The configuration and dimensions of a screw are shown in Fig. 3 and Table 1, respectively. The testing block had dimensions of $50 \mathrm{~mm}$ in width $\times 50 \mathrm{~mm}$ in length. The 7.5-mm- and 10-mm-thick metal blocks were made of aluminium and had a 3.5-mm deep countersink in the middle to ensure consistent thickness of the metal plate. As consequence, the screw penetration into the material was $17.5 \mathrm{~mm}$ for the specimen with the $7.5-\mathrm{mm}$ thick metal plate on top, and $15 \mathrm{~mm}$ for the specimen with 10-mm-thick metal plate on top. Flathead low-carbon-steel wood screws were used for this study (ANSI/ASME B18.6.1 2016) and each screw was used only once.

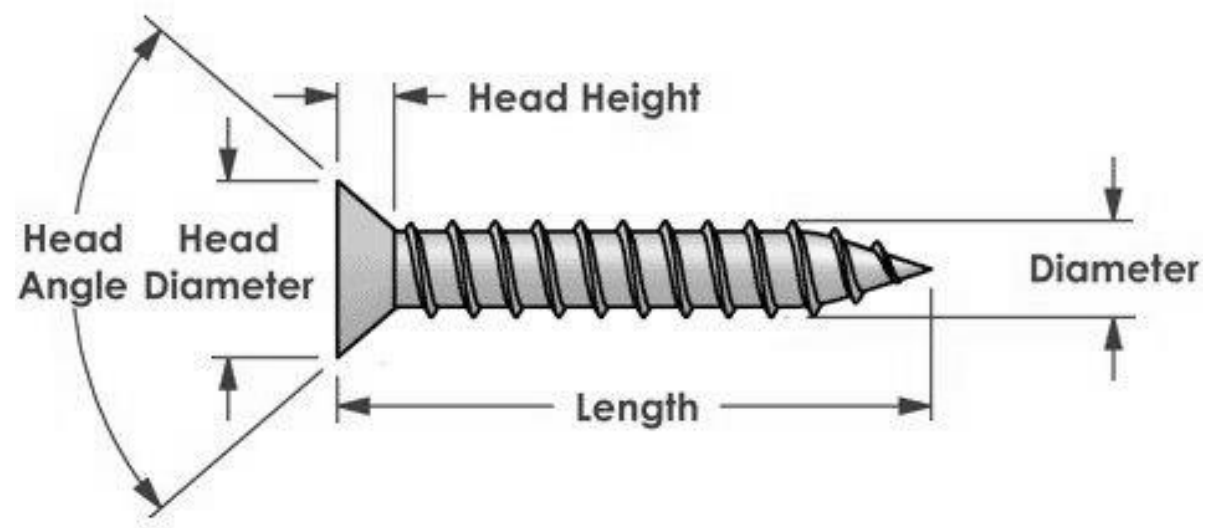

Fig. 3. Configuration of a wood screw

Table 1. Critical Dimensions of the Screw Used in this Study

\begin{tabular}{|l|c|c|c|c|c|c|}
\hline & $\begin{array}{c}\text { Length } \\
(\mathbf{m m})\end{array}$ & $\begin{array}{c}\text { Head Angle } \\
\left(\mathbf{(}^{\circ}\right)\end{array}$ & $\begin{array}{c}\text { Head } \\
\text { Height } \\
(\mathbf{m m})\end{array}$ & $\begin{array}{c}\text { Head } \\
\text { Diameter } \\
(\mathbf{m m})\end{array}$ & $\begin{array}{c}\text { Diameter } \\
(\mathbf{m m})\end{array}$ & $\begin{array}{c}\text { Number of } \\
\text { Threads }\end{array}$ \\
\hline Actual dimensions & $25.1(1)$ & $82^{\circ}(2)$ & $3.3(2)$ & $6.85(2)$ & $3.52(1)$ & 12 \\
\hline \multicolumn{7}{|l}{ Values in parentheses are coefficient of variation (\%) } \\
\hline
\end{tabular}

\section{Experimental Design}

A four-factor factorial experiment was designed with 10 replications per combination to evaluate treatment factors on SET and STT when driving screws into the face of PW. The four factors were number of PW layers, pilot hole diameter, pilot hole depth, and thickness of the metal plate.

The complete interaction model for the four-factor completely randomized design is given as Eq. 1,

$$
\begin{gathered}
Y_{\mathrm{ijklm}}=\mu+\alpha_{\mathrm{i}}+\beta_{j}+\gamma_{k}+\delta_{1}+(\alpha \beta)_{\mathrm{ij}}+(\alpha \gamma)_{\mathrm{ik}}+(\alpha \delta)_{\mathrm{il}}+(\beta \gamma)_{\mathrm{jk}}+ \\
(\beta \delta)_{\mathrm{j} 1}+(\gamma \delta)_{\mathrm{kl}}+(\alpha \beta \gamma)_{\mathrm{ijk}}+(\alpha \beta \delta)_{\mathrm{ijl}}+(\alpha \gamma \delta)_{\mathrm{ikl}}+(\beta \gamma \delta)_{\mathrm{jkl}}+(\alpha \beta \gamma \delta)_{\mathrm{ijkl}}+\varepsilon_{\mathrm{ijklm}}
\end{gathered}
$$

where $Y_{\mathrm{ijklm}}$ is the screw-driving torque, $\mu$ is overall mean of SET and STT $(\mathrm{N} \cdot \mathrm{m}), \alpha_{\mathrm{i}}$ is a continuous variable representing the effect of number of PW layers ( $\mathrm{i}=7$ and 9 layers), $\beta_{\mathrm{j}}$ is a continuous variable representing the effect of pilot hole diameter $(\mathrm{j}=3.0$ and $3.5 \mathrm{~mm})$, $\gamma_{\mathrm{k}}$ is a continuous variable representing the effect of pilot hole depth $(\mathrm{k}=60$ and $80 \%$ of specimen thickness), $\delta_{1}$ is a continuous variable representing the effect of thickness of metal 
plate $(1=7.5$ and $10 \mathrm{~mm}), \varepsilon \mathrm{jklm}$ is a random term, and $\mathrm{m}=10$ replicates, the rest of the terms are two-factor, three-factor, and four-factor interactions.

The face of a specimen was the PW panel surface. Thus, a total of 160 screwdriving tests were performed on $160 \mathrm{PW}$ testing blocks, and 320 data points for torques were collected. The protected least significant difference (LSD) multiple comparison procedure was also performed, followed by an analysis of variance (ANOVA) to compare the means and whether there was any significant interaction between the factors. Otherwise, the main effects were observed. All the statistical analyses were performed at a 5\% significance level. All data were statistically analysed (SAS 9.4, SAS Institute, Cary, NC, USA).

\section{Specimen Preparation and Torque Measurement}

All testing blocks were cut from half-size sheets and conditioned at $20 \pm 3{ }^{\circ} \mathrm{C}$ and $65 \pm 5 \%$ relative humidity in a climate chamber for two weeks in accordance with ASTM 1761-06 (2010).

The pilot holes were drilled into the surface of each testing block to guide to the screws in accordance with ASTM D4442-92 (2010) and ASTM D1037-06 (2010). The pilot hole diameters were 3.0 and $3.2 \mathrm{~mm}$, while the pilot hole depths were 60 and $80 \%$ of total thickness of the specimens. All torque measurements were performed immediately after the pilot holes had been drilled into the PW face testing blocks.

The torque measurement apparatus consisted of three different Kraft form adjustable torque screwdrivers, varied based on the torque ranges (Wera, Wuppertal, Germany). The torque-controlled screwdrivers had ranges from 0.3 to $1.2 \mathrm{~N} \cdot \mathrm{m}, 1.2$ to 3.0 $\mathrm{N} \cdot \mathrm{m}$, and 3.0 to $6.0 \mathrm{~N} \cdot \mathrm{m}$ (Fig. 4). They were adjusted by hand to the required torque value. They had distinctly audible and noticeable excess-load signals when the required torque was reached. The measurement accuracy was within $\pm 6 \%$ accordance with the standard of ISO 6789-2 (2017).

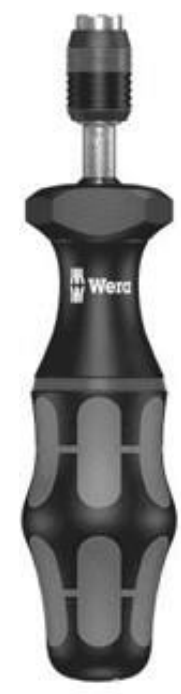

(a)

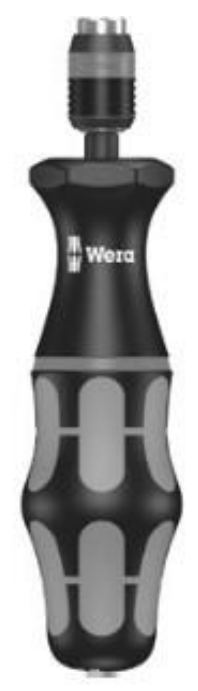

(b)

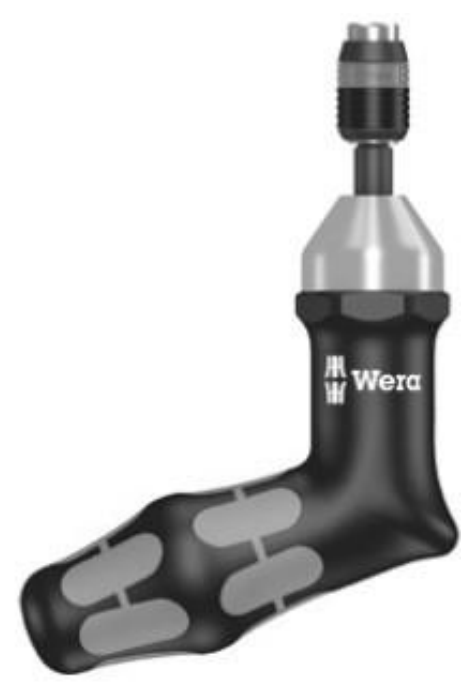

(c)

Fig. 4. (a) Pre-set torques from 0.1 to $1.2 \mathrm{~N} \cdot \mathrm{m}$; (b) 1.2 to $3.0 \mathrm{~N} \cdot \mathrm{m}$; and (c) 3.0 to $6.0 \mathrm{~N} \cdot \mathrm{m}$ 


\section{RESULTS AND DISCUSSION}

\section{Mean Driving Torque Comparisons}

The mean SET and STT values of driving screws into faces of PW materials for each treatment combination of thickness of metal plate by pilot hole diameter, by number of PW layers, and by pilot hole depth were evaluated in this study (Table 2). Table 2 also shows the ratio between STT and SET.

The mean SET values ranged from 0.31 to $0.69 \mathrm{~N} \cdot \mathrm{m}$, whereas mean STT values ranged from 0.495 to $4.7 \mathrm{~N} \cdot \mathrm{m}$. The ratios of STT/SET were between 2 and 5 in PW with seven layers, whereas the ratios were between 4 and 7 in PW with 9 layers. In one study, it was indicated that there was a need for more skilled and trained operators to drive screws into the material when the ration of STT/SET was lower than three (Robert 2010). The ratios greater than 3 are suitable for high volume production with power tools (Robert 2010).

Table 2 indicates that the STT had higher values than SET. Therefore, the ANOVA and mean comparisons were performed on SET and STT to test whether any difference existed between the groups. A four-factor ANOVA was performed using general linear model (GLM) procedure for each data set at the 5\% significance level to analyse the four main effects, and their interactions on the means of SET and STT for driving screws into faces of the evaluated PW material. Table 3 summarizes ANOVA results obtained from the GLM procedure performed on SET and STT data sets within each of two pilot hole diameter levels.

Table 2. Mean Values of SET and STT of Driving Screws into Faces of Particleboard Materials Evaluated in this Study

\begin{tabular}{|c|c|c|c|c|c|c|}
\hline \multirow{2}{*}{$\begin{array}{c}\text { Number } \\
\text { of } \\
\text { Layers }\end{array}$} & \multirow{2}{*}{$\begin{array}{l}\text { Pilot Hole } \\
\text { Diameter } \\
\text { (mm) }\end{array}$} & \multirow{2}{*}{$\begin{array}{l}\text { Pilot Hole } \\
\text { Depth } \\
(\%)\end{array}$} & \multirow{2}{*}{$\begin{array}{l}\text { Thickness } \\
\text { of Metal } \\
\text { Plate (mm) }\end{array}$} & \multicolumn{2}{|c|}{ Torque Type $(\mathrm{N} \cdot \mathrm{m})$} & \multirow{2}{*}{$\begin{array}{c}\text { Ratio } \\
\text { STT/SET }\end{array}$} \\
\hline & & & & SET & STT & \\
\hline \multirow{8}{*}{7} & \multirow[t]{4}{*}{ ( } & \multirow{2}{*}{60} & 7.5 & $0.360(14)$ & $1.440(17)$ & 4 \\
\hline & & & 10 & $0.465(14)$ & $1.620(8)$ & 3 \\
\hline & & \multirow{2}{*}{80} & 7.5 & $0.325(8)$ & $1.025(14)$ & 3 \\
\hline & & & 10 & $0.350(7)$ & $1.530(8)$ & 5 \\
\hline & \multirow{4}{*}{3.5} & \multirow{2}{*}{60} & 7.5 & $0.335(7)$ & $1.155(10)$ & 3 \\
\hline & & & 10 & $0.505(6)$ & $1.295(10)$ & 3 \\
\hline & & \multirow{2}{*}{80} & 7.5 & $0.305(7)$ & $0.495(11)$ & 2 \\
\hline & & & 10 & $0.320(8)$ & $1.150(9)$ & 4 \\
\hline \multirow{8}{*}{9} & \multirow{4}{*}{3.0} & \multirow{2}{*}{60} & 7.5 & $0.620(6)$ & $3.800(3)$ & 6 \\
\hline & & & 10 & $0.690(10)$ & $4.700(7)$ & 7 \\
\hline & & \multirow{2}{*}{80} & 7.5 & $0.305(5)$ & $1.440(16)$ & 5 \\
\hline & & & 10 & $0.420(13)$ & $1.610(16)$ & 4 \\
\hline & \multirow{4}{*}{3.5} & \multirow{2}{*}{60} & 7.5 & $0.485(8)$ & $3.200(6)$ & 7 \\
\hline & & & 10 & $0.580(17)$ & $4.200(9)$ & 7 \\
\hline & & \multirow{2}{*}{80} & 7.5 & $0.300(1)$ & $1.150(13)$ & 4 \\
\hline & & & 10 & $0.315(8)$ & $1.325(11)$ & 4 \\
\hline
\end{tabular}


Table 3. Summary of ANOVA Results Obtained from the GLM Procedure Performed on Three Factors for SET and STT Data Sets within Each of Two Pilot Hole Diameters

\begin{tabular}{|c|c|c|c|c|}
\hline \multirow{2}{*}{ Source } & \multicolumn{2}{|c|}{ SET } & \multicolumn{2}{c|}{ STT } \\
\cline { 2 - 5 } & F-value & p-value & F-value & p-value \\
\hline Number of layers & 180.16 & $<0.0001$ & 2177.18 & $<0.0001$ \\
\hline Pilot hole diameter & 48.72 & $<0.0001$ & 161.94 & $<0.0001$ \\
\hline Pilot hole depth & 119.18 & $<0.0001$ & 220.12 & $<0.0001$ \\
\hline Thickness of metal plate & 627.76 & $<0.0001$ & 2166.05 & $<0.0001$ \\
\hline 2-way interaction & 0.13 to 143.78 & 0.7209 to $<$ & 0.38 to 1303.61 & 0.5380 to $<0.0001$ \\
& & 0.0001 & & \\
\hline 3-way interaction & 5.41 to 12.81 & 0.0241 to & 0.01 to 91.00 & 0.9841 to $<0.0001$ \\
& & 0.0005 & & 0.2582 \\
\hline 4-way interaction & 0.80 & 0.3724 & 1.29 & \\
\hline
\end{tabular}

In addition, four main effects of each of SET and STT were statistically significant with their p-values of $<0.0001$. Further checking of the magnitudes of F-values for all significant factors in the SET data sets indicated that the thickness of metal plate had a much greater F-value of 627.76 than number of layers, with an F-value of 180.16, pilot hole depth with an F-value of 119.18, and pilot hole diameter with an F-value of 48.72 (Table 3). For the STT data set, the number of layers had a much greater F-value of 2177.18 than thickness of metal plate, with an F-value of 2166.05, pilot hole depth with F-value of 220.12, and pilot hole diameter with an F-value of 161.94 (Table 3).

This could imply that the significance of the thickness of the metal plate and the number of PW layers effect on SET and STT was much stronger than the other two factors of pilot hole diameter and pilot hole depth. Hence, the thickness of metal plate effect on SET and STT was evaluated relative to the mean comparisons of the main effects. The mean comparison results indicated that in general, the specimen with the 10-mm-thick metal plate had a significantly higher SET and STT than corresponding ones with the 7.5$\mathrm{mm}$-thick metal plate for all 16 combinations evaluated. The effects of pilot hole diameter and pilot hole depth on the SET and STT values of screws used for each of the two data sets in Table 4 were analysed by considering its corresponding non-significant four-way interaction, because the nature of conclusions from interpretation of main effects depend on the relative magnitudes of the interaction and individual main effects (Freund et al. 2010). Mean comparison results of SET and STT for thickness of metal plate, number of PW layers, pilot hole diameter, and pilot hole depth were summarized in Tables 4, 5, 6, and 7, respectively. These results were based on a one-way classification created with 16 treatment combinations with respect to the four-factor interaction for each data set.

The protected LSD multiple comparisons procedure at the 5\% significance level was performed to compute the smallest significant difference among the means, as if these means had been the only means to be compared, and to declare significant any difference greater than the LSD value. The LSD values of 0.039 and $0.1755 \mathrm{~N} \cdot \mathrm{m}$ were used to determine mean differences among different treatments for SET and STT data sets (Table 4). Tables $4,5,6$, and 7 show the mean comparisons by using a single LSD value of 0.039 and $0.1755 \mathrm{~N} \cdot \mathrm{m}$ for SET and STT data sets, respectively. 


\section{Thickness of Metal Plate Effects}

Table 4 demonstrates the mean comparison of SET and STT for the specimen with the thickness of metal plate compared to the factors of number of layers, pilot hole depth, and pilot hole diameter. The results indicated that the SET and STT were lower in the specimens with the 7.5-mm-thick metal plate used compared with the 10-mm-thick metal plate used in all combinations. There was no significant difference in SET of the specimens with 7.5-mm- and 10-mm-thick metal plates used in which the pilot hole depth was $80 \%$ of the total thickness of the specimen in all pilot hole diameters and number of layers, except for one case. The SET was statistically higher in the 9 layered specimens with the $10-\mathrm{mm}$ metal plate used than the corresponding one with the 3 -mm pilot hole diameter.

Table 4. Mean Comparisons of SET and STT for Thickness of Metal Plate Within Each Combination of Pilot Hole Depth, Pilot Hole Diameter, and Number of Layers

\begin{tabular}{|c|c|c|c|c|c|c|}
\hline \multirow{4}{*}{$\begin{array}{c}\text { Number } \\
\text { of } \\
\text { Layers }\end{array}$} & \multirow{4}{*}{$\begin{array}{l}\text { Pilot Hole } \\
\text { Diameter } \\
(\mathrm{mm})\end{array}$} & \multirow{4}{*}{$\begin{array}{l}\text { Pilot Hole } \\
\text { Depth } \\
(\%)\end{array}$} & \multicolumn{4}{|c|}{ Torque Type $(\mathrm{N} \cdot \mathrm{m})$} \\
\hline & & & \multicolumn{2}{|c|}{ SET } & \multicolumn{2}{|c|}{ STT } \\
\hline & & & \multicolumn{4}{|c|}{ Thickness of metal plate $(\mathrm{mm})$} \\
\hline & & & 7.5 & 10 & 7.5 & 10 \\
\hline \multirow{4}{*}{7} & \multirow{2}{*}{3.0} & 60 & $0.36(\mathrm{~B})$ & $0.47(\mathrm{~A})$ & $1.44(\mathrm{~B})$ & $1.62(\mathrm{~A})$ \\
\hline & & 80 & $0.33(\mathrm{~A})$ & $0.35(\mathrm{~A})$ & $1.03(\mathrm{~B})$ & $1.53(\mathrm{~A})$ \\
\hline & \multirow{2}{*}{3.5} & 60 & $0.34(\mathrm{~B})$ & $0.51(\mathrm{~A})$ & $1.16(\mathrm{~A})$ & $1.30(\mathrm{~A})$ \\
\hline & & 80 & $0.31(\mathrm{~A})$ & $0.32(\mathrm{~A})$ & $0.50(\mathrm{~B})$ & $1.15(\mathrm{~A})$ \\
\hline \multirow{4}{*}{9} & \multirow{2}{*}{3.0} & 60 & $0.62(\mathrm{~B})$ & $0.69(\mathrm{~A})$ & $3.80(\mathrm{~B})$ & $4.70(\mathrm{~A})$ \\
\hline & & 80 & $0.31(\mathrm{~B})$ & $0.42(\mathrm{~A})$ & $1.44(\mathrm{~A})$ & $1.61(\mathrm{~A})$ \\
\hline & \multirow{2}{*}{3.5} & 60 & $0.49(\mathrm{~B})$ & $0.58(\mathrm{~A})$ & $3.20(\mathrm{~B})$ & $4.20(\mathrm{~A})$ \\
\hline & & 80 & $0.30(\mathrm{~A})$ & $0.32(\mathrm{~A})$ & $1.15(\mathrm{~A})$ & $1.33(\mathrm{~A})$ \\
\hline
\end{tabular}

Table 5. Mean Comparisons of SET and STT for Number of Layers Within Each Combination of Pilot Hole Depth, Thickness of Metal Plate, and Pilot Hole Diameter

\begin{tabular}{|c|c|c|c|c|c|c|}
\hline \multirow{4}{*}{$\begin{array}{c}\text { Pilot } \\
\text { Hole } \\
\text { Diameter } \\
(\mathrm{mm})\end{array}$} & \multirow{4}{*}{$\begin{array}{l}\text { Thickness } \\
\text { of Metal } \\
\text { Plate }(\mathrm{mm})\end{array}$} & \multirow{4}{*}{$\begin{array}{l}\text { Pilot Hole } \\
\text { Depth } \\
(\%)\end{array}$} & \multicolumn{4}{|c|}{ Torque Type $(\mathrm{N} \cdot \mathrm{m})$} \\
\hline & & & \multicolumn{2}{|c|}{ SET } & \multicolumn{2}{|c|}{ STT } \\
\hline & & & \multicolumn{4}{|c|}{ Number of Layers } \\
\hline & & & 7 & 9 & 7 & 9 \\
\hline \multirow{4}{*}{3.0} & \multirow{2}{*}{7.5} & 60 & $0.36(\mathrm{~B})$ & $0.62(\mathrm{~A})$ & $1.44(\mathrm{~B})$ & $3.80(\mathrm{~A})$ \\
\hline & & 80 & $0.33(\mathrm{~A})$ & $0.31(\mathrm{~A})$ & $1.03(\mathrm{~B})$ & $1.44(\mathrm{~A})$ \\
\hline & \multirow{2}{*}{10} & 60 & $0.47(\mathrm{~B})$ & $0.69(\mathrm{~A})$ & $1.62(\mathrm{~B})$ & $4.70(\mathrm{~A})$ \\
\hline & & 80 & $0.35(\mathrm{~B})$ & $0.42(\mathrm{~A})$ & $1.53(\mathrm{~A})$ & $1.61(\mathrm{~A})$ \\
\hline \multirow{4}{*}{3.5} & \multirow{2}{*}{7.5} & 60 & $0.34(\mathrm{~B})$ & $0.49(\mathrm{~A})$ & $1.16(\mathrm{~B})$ & $3.20(\mathrm{~A})$ \\
\hline & & 80 & $0.31(\mathrm{~A})$ & $0.30(\mathrm{~A})$ & $0.50(\mathrm{~B})$ & $1.15(\mathrm{~A})$ \\
\hline & \multirow{2}{*}{10} & 60 & $0.51(\mathrm{~B})$ & $0.58(\mathrm{~A})$ & $1.30(\mathrm{~B})$ & $4.20(\mathrm{~A})$ \\
\hline & & 80 & $0.32(\mathrm{~A})$ & $0.32(A)$ & $1.15(\mathrm{~B})$ & $1.33(\mathrm{~A})$ \\
\hline
\end{tabular}




\section{Number of Layers' Effects}

The results of mean comparisons indicated that the STT was higher in the 9-layered PW than the corresponding ones with 7 layers in all combinations. The same trend was followed for SET, except in three cases. In these cases, the SET in the specimens constructed with 7 and 9 layers did not statistically differ from each other when $80 \%$ pilot hole depth was drilled. In the case of STT, it was almost three times higher in the specimens with 9 layers than the ones with 7 layers when they were drilled at $60 \%$ pilot hole depth in the specimens with 10-mm metal plate for both pilot hole diameters (Table 5). This was due to the penetration depth of the screw into the PW material. The thicker PW material held the screw better than the thinner material.

\section{Pilot Hole Diameter Effects}

In general, the mean SET and STT values of screws driven into the face of the PW material drilled by the 3-mm pilot hole diameter were higher than the corresponding ones with the 3.5-mm pilot hole in all treatment combinations (Table 6). The ratio of the 3-mm / 3.5-mm pilot hole diameter ranged from 6 to $31 \%$ for the SET values in almost all combinations. This can be explained by the narrower pilot hole diameter, as having $3 \mathrm{~mm}$ still provides some room for the screw to be driven into the material to tighten the pieces together. For STT values, the ratio ranged from 12 to $33 \%$ in all treatment combinations except for one case in the 7 layered PW when the $80 \%$ pilot hole depth used. This case had the ratio of $106 \%$, which can be explained by limited particles in the pilot hole for the screw to hold enough to pull the pieces together.

Table 6. Mean Comparisons of SET and STT for Screwdriver Air Pressure Within Each Combination of Pilot Hole Diameter, Thickness of Metal Plate, and Vertical Driving Force

\begin{tabular}{|c|c|c|c|c|c|c|}
\hline \multirow{4}{*}{$\begin{array}{c}\text { Number } \\
\text { of } \\
\text { Layers }\end{array}$} & \multirow{4}{*}{$\begin{array}{l}\text { Thickness } \\
\text { of Metal } \\
\text { Plate }(\mathrm{mm})\end{array}$} & \multirow{4}{*}{$\begin{array}{l}\text { Pilot Hole } \\
\text { Depth } \\
\text { (\%) }\end{array}$} & \multicolumn{4}{|c|}{ Torque Type $(\mathrm{N} \cdot \mathrm{m})$} \\
\hline & & & \multicolumn{2}{|c|}{ SET } & \multicolumn{2}{|c|}{ STT } \\
\hline & & & \multicolumn{4}{|c|}{ Pilot Hole Diameter $(\mathrm{mm})$} \\
\hline & & & 3.0 & 3.5 & 3.0 & 3.5 \\
\hline \multirow{4}{*}{7} & \multirow{2}{*}{7.5} & 60 & $0.36(\mathrm{~A})$ & $0.34(\mathrm{~A})$ & $1.44(\mathrm{~A})$ & $1.16(\mathrm{~B})$ \\
\hline & & 80 & $0.33(\mathrm{~A})$ & $0.31(\mathrm{~A})$ & $1.03(\mathrm{~A})$ & $0.50(\mathrm{~B})$ \\
\hline & \multirow{2}{*}{10} & 60 & $0.47(\mathrm{~B})$ & $0.51(\mathrm{~A})$ & $1.62(\mathrm{~A})$ & $1.30(\mathrm{~B})$ \\
\hline & & 80 & $0.35(\mathrm{~A})$ & $0.32(\mathrm{~A})$ & $1.53(\mathrm{~A})$ & $1.15(\mathrm{~B})$ \\
\hline \multirow{4}{*}{9} & \multirow{2}{*}{7.5} & 60 & $0.62(\mathrm{~A})$ & $0.49(\mathrm{~B})$ & $3.80(\mathrm{~A})$ & $3.20(\mathrm{~B})$ \\
\hline & & 80 & $0.31(\mathrm{~A})$ & $0.30(\mathrm{~A})$ & $1.44(\mathrm{~A})$ & $1.15(\mathrm{~B})$ \\
\hline & \multirow{2}{*}{10} & 60 & $0.69(\mathrm{~A})$ & $0.58(\mathrm{~B})$ & $4.70(\mathrm{~A})$ & $4.20(\mathrm{~B})$ \\
\hline & & 80 & $0.42(\mathrm{~A})$ & $0.32(\mathrm{~B})$ & $1.61(\mathrm{~A})$ & $1.33(\mathrm{~B})$ \\
\hline
\end{tabular}

\section{Pilot Hole Depth Effects}

In general, the SET and STT values of screws driven into the face of the PW material at the dipper pilot hole depth (80\%) were lower than the corresponding ones at the $60 \%$ pilot hole diameter in all treatment combinations. Mean comparison of SET and STT based on the pilot hole depth demonstrated that there was significant increase in SET and STT values when the pilot hole was drilled from $60 \%$ to $80 \%$ in the face of the PW material. 
The STT values were almost three times higher in the $60 \%$ pilot hole depth than the corresponding ones at $80 \%$ pilot hole depth at $10 \mathrm{~mm}$ thickness of metal plate used by all pilot hole diameters when the screw were driven into the face of 9-layered PW material. Further torqueing the screw into the material can cause damage to the screw and material, which will lose tightening and reduce the STT values.

Table 7. Mean Comparisons of SET and STT for Screwdriver Air Pressure Within Each Combination of Pilot Hole Diameter, Thickness of Metal Plate, and Vertical Driving Force

\begin{tabular}{|c|c|c|c|c|c|c|}
\hline \multirow{4}{*}{$\begin{array}{c}\text { Number } \\
\text { of } \\
\text { Layers }\end{array}$} & \multirow{4}{*}{$\begin{array}{c}\text { Pilot Hole } \\
\text { Diameter } \\
(\mathrm{mm})\end{array}$} & \multirow{4}{*}{$\begin{array}{l}\text { Thickness } \\
\text { of Metal } \\
\text { Plate }(\mathrm{mm})\end{array}$} & \multicolumn{4}{|c|}{ Torque Type $(\mathrm{N} \cdot \mathrm{m})$} \\
\hline & & & \multicolumn{2}{|c|}{ SET } & \multicolumn{2}{|c|}{ STT } \\
\hline & & & \multicolumn{4}{|c|}{ Pilot Hole Depth (\%) } \\
\hline & & & 60 & 80 & 60 & 80 \\
\hline \multirow{4}{*}{7} & \multirow{2}{*}{3.0} & 7.5 & $0.36(\mathrm{~A})$ & $0.33(\mathrm{~A})$ & $1.44(\mathrm{~A})$ & $1.03(\mathrm{~B})$ \\
\hline & & 10 & $0.47(\mathrm{~A})$ & $0.35(\mathrm{~B})$ & $1.62(\mathrm{~A})$ & $1.53(\mathrm{~A})$ \\
\hline & \multirow{2}{*}{3.5} & 7.5 & $0.34(\mathrm{~A})$ & $0.31(\mathrm{~A})$ & $1.56(\mathrm{~A})$ & $0.50(\mathrm{~B})$ \\
\hline & & 10 & $0.51(\mathrm{~A})$ & $0.32(\mathrm{~B})$ & $1.30(\mathrm{~A})$ & $1.15(\mathrm{~A})$ \\
\hline \multirow{4}{*}{9} & \multirow[b]{2}{*}{3.0} & 7.5 & $0.62(\mathrm{~A})$ & $0.31(\mathrm{~B})$ & $3.80(\mathrm{~A})$ & $1.44(\mathrm{~B})$ \\
\hline & & 10 & $0.69(\mathrm{~A})$ & $0.42(\mathrm{~B})$ & $4.70(\mathrm{~A})$ & $1.61(\mathrm{~B})$ \\
\hline & \multirow{2}{*}{3.5} & 7.5 & $0.49(\mathrm{~A})$ & $0.30(\mathrm{~B})$ & $3.20(\mathrm{~A})$ & $1.15(\mathrm{~B})$ \\
\hline & & 10 & $0.58(\mathrm{~A})$ & $0.32(\mathrm{~B})$ & $4.20(\mathrm{~A})$ & $1.33(\mathrm{~B})$ \\
\hline
\end{tabular}

\section{Prediction Equation}

To quantify the effects of significant factors on SET and STT in the face of PW, the least squares regression technique of using the following power equation (Eq. 2) was proposed to fit to the individual test data points,

$$
T=a \times L^{b} \times P H^{c} \times P D^{d} \times S^{e}
$$

where $T$ is screw-driving torque $(\mathrm{N} \cdot \mathrm{m}), L$ is the number of $\mathrm{PW}$ layer, $P H$ is pilot hole diameter (mm), PD is the pilot hole depth, $S$ is thickness of metal plate $(\mathrm{mm})$, and $a, b, c$, $d$, and $e$ are regression fitting constants. The regression model proposed in this study could be a useful technique for deriving the relationship between screw-driving torques and their significant factors.

Table 8. Regression Coefficients and Associated $R^{2}$ Values for Derived Equations for Screw Driving Torques

\begin{tabular}{|c|c|c|c|c|c|c|}
\hline Screwdriving Torques & $\boldsymbol{a}$ & $\boldsymbol{b}$ & $\boldsymbol{c}$ & $\boldsymbol{d}$ & $\boldsymbol{e}$ & $\mathbf{R}^{\mathbf{2}}$ \\
\hline SET & -0.46868 & 0.762 & -0.69348 & 0.61823 & -0.57890 & 0.74 \\
\hline STT & -0.51974 & 2.90786 & -1.73938 & 0.96666 & -1.01100 & 0.82 \\
\hline
\end{tabular}

Table 8 gives the regression coefficients and coefficients of determination $\left(\mathrm{R}^{2}\right)$ of the derived equations for estimating SET and STT values of screw driven into the face of the PW material. The $\mathrm{R}^{2}$ values of 0.74 and 0.82 for SET and STT, respectively, suggested that derived equations could be useful for estimating mean SET and STT. In general, higher b values, as shown in Table 8, indicate that the number PW layers, which is the thickness 
of the PW material, affects both the SET and STT followed by the pilot hole depth. The SET and STT are less sensitive to pilot hole diameter and thickness of the metal plate compared to the other two factors.

\section{CONCLUSIONS}

1. The specimens with the 10 -mm-thick metal plate had a significantly higher mean seating torque (SET) and mean stripping torque (STT) than corresponding ones with the 7.5-mm-thick metal plates for all 16 treatment combinations evaluated.

2. The SET and STT values of screws driven into the face of 9-layered plywood (PW) were higher than the corresponding ones with 7 layers in all combinations.

3. The SET and STT values when using the pilot hole depth of $80 \%$ was lower than the corresponding ones at the $\mathbf{6 0 \%}$ pilot hole diameter in all treatment combinations.

4. The mean SET and STT obtained in this study could be predicted by the developed estimation equations.

5. A power equation was derived for the estimation of SET and STT constants using significant parameters, but it is limited to the PW material used in this study. Further validation is required if these derived equations are useful for general applications in other materials.

\section{ACKNOWLEDGMENTS}

This study was funded by the Zhejiang Natural Science Foundation in China (Grant number: LQ18C160002).

\section{REFERENCES CITED}

ANSI/ASME B18.6.1 (2016). "Wood screws (inch series)," American National Standards Institute, New York, NY, USA.

ASTM D1037-06 (2010). "Standard test methods for evaluating properties of wood-base fiber and particle panel materials," ASTM International, West Conshohocken, PA, USA.

ASTM D1761-06 (2010). "Standard test method for mechanical fasteners in wood," ASTM International, West Conshohocken, PA, USA.

ASTM D4442-92 (2010). "Standard test methods for direct moisture content measurement of wood and wood-base materials," ASTM International, West Conshohocken, PA, USA.

Armstrong, T., Bir, C., Foulke, J., Martin, B., Finsen, L., and Sjogaard, G. (1999). "Muscle responses to simulated torque reactions of hand-held power tools," Ergonomics 42(1), 146-159. DOI: 10.1080/001401399185856

Carroll, M. N. (1970). "Relationship between driving torque and screw-holding strength in particleboard and plywood," Forest Prod. J. 20(3), 24-29. 
Cederqvist, T., and Lindberg, M. (1993). "Screwdrivers and their use from a Swedish construction industry perspective," Appl. Ergon. 24(3), 148-157. DOI: 10.1016/00036870(93)90002-q

Chatterjee, D. S. (1987). "Repetition strain injury - A recent review," Occup. Med-C. 37(1), 100-105. DOI: 10.1093/occmed/37.1.100

Corlett, E. N. (1988). "Cumulative trauma disorders: A manual for musculoskeletal diseases of the upper limbs," Appl. Ergon. 19(4), 332. DOI: 10.1016/00036870(88)90086-5

Freund, R. J., Mohr, D., and Wilson, W. J. (2010). Statistical Methods: $3^{\text {rd }}$ Edition, Academic Press Inc., San Diego, CA, USA.

Herbert, R., Gerr, F., and Dropkin, J. (2000). "Clinical evaluation and management of work-related carpal tunnel syndrome," Am. J. Ind. Med. 37(1), 62-74. DOI: 10.1002/(sici)1097-0274(200001)37:1<62::aid-ajim6>3.0.co;2-d

ISO 6789-2 (2017). "Assembly tools for screws and nuts - Hand torque tools - Part 2: Requirements for calibration and determination of measurement uncertainty. International Organization for Standardization. Geneva, Switzerland.

Johnson, S. L., and Childress, L. J. (1988). "Powered screwdriver design and use: Tool, task, and operator effects," Appl. Ergon. 20(2), 147. DOI: 10.1016/00036870(89)90158-0

Kroemer, K. H. E. (1989). "Cumulative trauma disorders: Their recognition and ergonomics measures to avoid them," Appl. Ergon. 20(4), 274-280. DOI: 10.1016/0003-6870(89)90190-7

Kuang, F., Xing, Y., Wu, Z., and Zhang, J. (2017). "Characteristics of screwdriving torques in wood-plastic composites," Wood Fiber Sci. 49(2), 206-218.

National Particleboard Association (1968). Screw Holding of Particleboard (Tech. Bull. No. 3), National Particleboard Association, Washington, DC, USA.

Ortengren, R., Cederqvist, T., Lindberg, M., and Magnusson, B. (1991). "Workload in lower arm and shoulder when using manual and powered screwdrivers at different working heights," Int. J. Ind. Ergonom. 8(3), 225-235. DOI: 10.1016/01698141(91)90034-j

Robert, A. M. (2010). Plastic Part Design for Injection Molding: An Introduction, $2^{\text {nd }}$ Edition, Hanser Publications, Cincinnati, OH, USA.

Tor, O., Yu, X., and Zhang, J. (2015). "Characteristics of torques for driving screws into wood-based composites," Wood Fiber Sci. 47(1), 2-16.

Tor, O., Demirel, S., Hu, L., and Zhang, J. (2016). "Effects of driving torques on direct screw withdrawal resistance in OSB," Kast. Uni. J. Forest. Fac. 16(2), 438-446. DOI: 10.17475/kastorman.289754

Tor, O., Yu, X., Demirel, S., Hu, L., and Zhang, J. (2019). "Factors affecting critical screw-driving torques in particleboard," BioResources 14(3), 6645-6656. DOI: 10.15376/biores.14.3.6645-6656

Yu, X., Tor, O., Quin, F., Seale, D., and Zhang, J. (2015). "Screw-driving torques in particleboards," Wood Fiber Sci. 47(2), 17-30.

Article submitted: June 29, 2020; Peer review completed: August 29, 2020; Revised version received and accepted: September 4, 2020; Published: September 9, 2020.

DOI: 10.15376/biores.15.4.8121-8132 